\title{
Characterization of a Synergistic Interaction Between Two Cucurbit-Infecting Begomoviruses: Squash leaf curl virus and Watermelon chlorotic stunt virus
}

\author{
Tali Sufrin-Ringwald and Moshe Lapidot
}

Department of Vegetable Research, Institute of Plant Sciences, Agricultural Research Organization, Volcani Center, P. O. Box 6, Bet Dagan 50-250, Israel.

Accepted for publication 27 September 2010.

\begin{abstract}
Sufrin-Ringwald, T., and Lapidot, M. 2011. Characterization of a synergistic interaction between two cucurbit-infecting begomoviruses: Squash leaf curl virus and Watermelon chlorotic stunt virus. Phytopathology 101:281-289.

Squash leaf curl virus (SLCV) and Watermelon chlorotic stunt virus (WmCSV) are cucurbit-infecting bipartite begomoviruses. Both viruses are found in the eastern Mediterranean basin but the effects of dual infection of both viruses on melon (Cucumis melo L.) have not been described. 'Arava' melon plants were inoculated in the greenhouse, using whiteflies, with either SLCV, WmCSV, or both. Control plants were exposed to nonviruliferous whiteflies or not exposed at all. Following inoculation, plants were transplanted to a 50-mesh insect-proof nethouse and grown until fruit maturity. The experiment was performed in two

disappeared with time, and there was no effect on plant height. WmCSVinfected plants developed disease symptoms that became more obvious with time, and plants were somewhat shorter than control plants in the spring but not in the summer. SLCV had no effect on yield, regardless of season. WmCSV had no statistically significant effect on yield in the spring but, in the summer, reduced yield by $22 \%$, on average. Dualinoculated plants showed a synergistic interaction between the two viruses. They developed disease symptoms that were more pronounced than WmCSV alone, with plants being shorter than control plants by 20 to $25 \%$ regardless of season. Moreover, the yield of dual-inoculated plants was reduced on average by $21 \%$ in the spring and $54 \%$ in the summer, and fruit appearance was adversely affected. Dual inoculation did not affect WmCSV DNA level but SLCV DNA level was increased severalfold by the presence of WmCSV.
\end{abstract} melon-growing seasons: spring, transplant in May and harvest in July; and summer, transplant in August and harvest in October. Following inoculation, SLCV-infected melon plants showed mild symptoms that
Additional keyword: synergism.
Begomoviruses (family Geminiviridae, genus Begomovirus) are one of the largest and most economically important groups of plant-infecting viruses. Their genome is composed of either one (monopartite) or two (bipartite) molecules of circular singlestranded DNA, termed DNA-A and DNA-B, and the viruses are transmitted in a persistent and circulative manner by the whitefly Bemisia tabaci (Gennadius) $(11,14)$. Due to the global spread of their vector, begomoviruses have become a major threat to vegetable crops in tropical and semitropical regions $(16,21,29$, 31,33). In 2002, two cucurbit-infecting bipartite begomoviruses, Watermelon chlorotic stunt virus (WmCSV) and Squash leaf curl virus (SLCV), were identified in Israel $(1,3)$. The Israeli isolates of both viruses were cloned, sequenced, and characterized (1). During approximately the last 5 years, both viruses became established in the eastern Mediterranean basin $(2,13)$.

SLCV affects mostly squash plants (Cucurbita pepo L.); disease symptoms include severely curled leaves with mottled areas, leaves with shorter petioles, sterility, and, in some cultivars, distortion of fruit. WmCSV affects mostly watermelon plants (Citrullus lanatus (Thunb.) Matsum. \& Nakai); disease symptoms include vein yellowing, yellowing and curling of leaves, severe plant stunting, and a drastic reduction of fruit yield. However,

Corresponding author: M. Lapidot; E-mail address: lapidotm@volcani.agri.gov.il

* The $\boldsymbol{e}$-Xtra logo stands for "electronic extra" and indicates that Figures 1, 2, and 3 appear in color online.

doi:10.1094/PHYTO-06-10-0159

(C) 2011 The American Phytopathological Society the host range of both WmCSV and SLCV includes all of the major cultivated cucurbit crops: melon (Cucumis melo), squash, watermelon, cucumber (C. sativus L.), pumpkin (Cucurbita maxima Duchesne), and tropical pumpkin (C. moschata Duchesne) $(1,4)$.

Prior to their spread to Israel and its neighbors in the eastern Mediterranean, SLCV was prevalent mainly in Central and North America (7), while WmCSV was detected only in Sudan, Yemen, and Iran (4). Hence, this is the first documentation that these two bipartite begomoviruses-WmCSV (an Old World virus) and SLCV (a New World virus) - are present in the same geographical region. This, and the overlap in the host range of these viruses, raises the question of what would happen if both viruses infect the same plant. Moreover, in a survey of cucurbit fields in Israel conducted in 2005 to 2009, samples were collected from symptomatic cucurbit plants and, in many cases, both viruses were found infecting the same plant (M. Lapidot, unpublished data). Mixed infections with two or more viruses infecting the same plant host are quite common in the field $(19,22,26,27,30)$. There are several possible outcomes to a viral mixed infection. One possibility is that the viruses do not interact at all with each other. Another is that one virus inhibits or interferes with the infection cycle of the other virus (22). A third possibility is that one virus enhances infection by the other virus, a phenomenon known as synergism $(22,26,28)$. Synergism between two viruses usually results in elevated viral titer of one or both of the involved viruses, and often will result in disease symptoms that are more severe than those either virus alone can induce.

Melon is an important cash crop in Israel and, indeed, around much of the Mediterranean Basin. SLCV can induce severe 
disease on squash in a single infection and WmCSV can induce a particularly severe disease on watermelon in a single infection. Although neither virus alone, at present, has much impact on melon crops, a synergistic interaction between them on melon fruit could have severe economic ramifications for the region. The objective of this manuscript is to describe the effects of dual SLCV and WmCSV infection on melon plants.

\section{MATERIALS AND METHODS}

Viruses. The viruses were maintained in isolated infected plants grown in an insect-proof greenhouse. Cultures of the Israeli isolate of SLCV (GenBank accession no. HQ184436 and HQ184437) were maintained in squash plants, C. pepo subsp. pepo Cocozelle Group 'Ma'yan' (Hazera Genetics, Berurim, Israel), and cultures of WmCSV (GenBank accession no. EF201809 and EF201810) were maintained in watermelon plants, Citrullus lanatus 'Malali' (Hazera Genetics) (1).

Whitefly maintenance and inoculation of plants. Whitefly (B. tabaci, biotype B) colonies were reared on cotton (Gossypium hirsutum L.) plants grown in muslin-covered cages maintained inside an insect-proof greenhouse. Adult whiteflies were provided a 48-h acquisition access period (AAP) on SLCV-infected squash source plants or on WmCSV-infected watermelon source plants, separately, followed by a 48 -h inoculation access period (IAP) on melon Cucumis melo 'Arava' (Hazera Genetics) test plants with two true leaves. Following the IAP, the whiteflies were removed by treating plants with imidacloprid (Confidor; Bayer, Leverkusen, Germany). The plants were kept in the greenhouse for a 1-week recovery period. ,

The study included five treatments: (i) control = noninfected plants; (ii) whiteflies = plants treated with virus-free whiteflies; (iii) SLCV = plants treated with whiteflies carrying SLCV; (iv) $\mathrm{WmCSV}=$ plants treated with whiteflies carrying WmCSV; and (v) $\mathrm{Wm}+\mathrm{SL}=$ plants treated at the same time with whiteflies carrying SLCV together with whiteflies carrying WmCSV.

Yield trials. After the recovery period, the plants were transplanted to 10-liter pots filled with Lava soil grade 0-4 and placed in a 50-mesh insect-proof nethouse at Bet Dagan (central Israel). There were four experiments in two successive years. The plants were either transplanted in May and grown through July (two spring experiments) or transplanted in August and grown through October (two summer experiments). The plants were trained to a single stem and suspended on a string tied to a support $2 \mathrm{~m}$ above the top of the pots. Once the plants reached the top of the string, the tips of the plants were removed. Each experiment consisted of 75 melon plants, 15 plants per treatment. Each plant served as a replicate and 15 plants from each treatment were randomly dis-
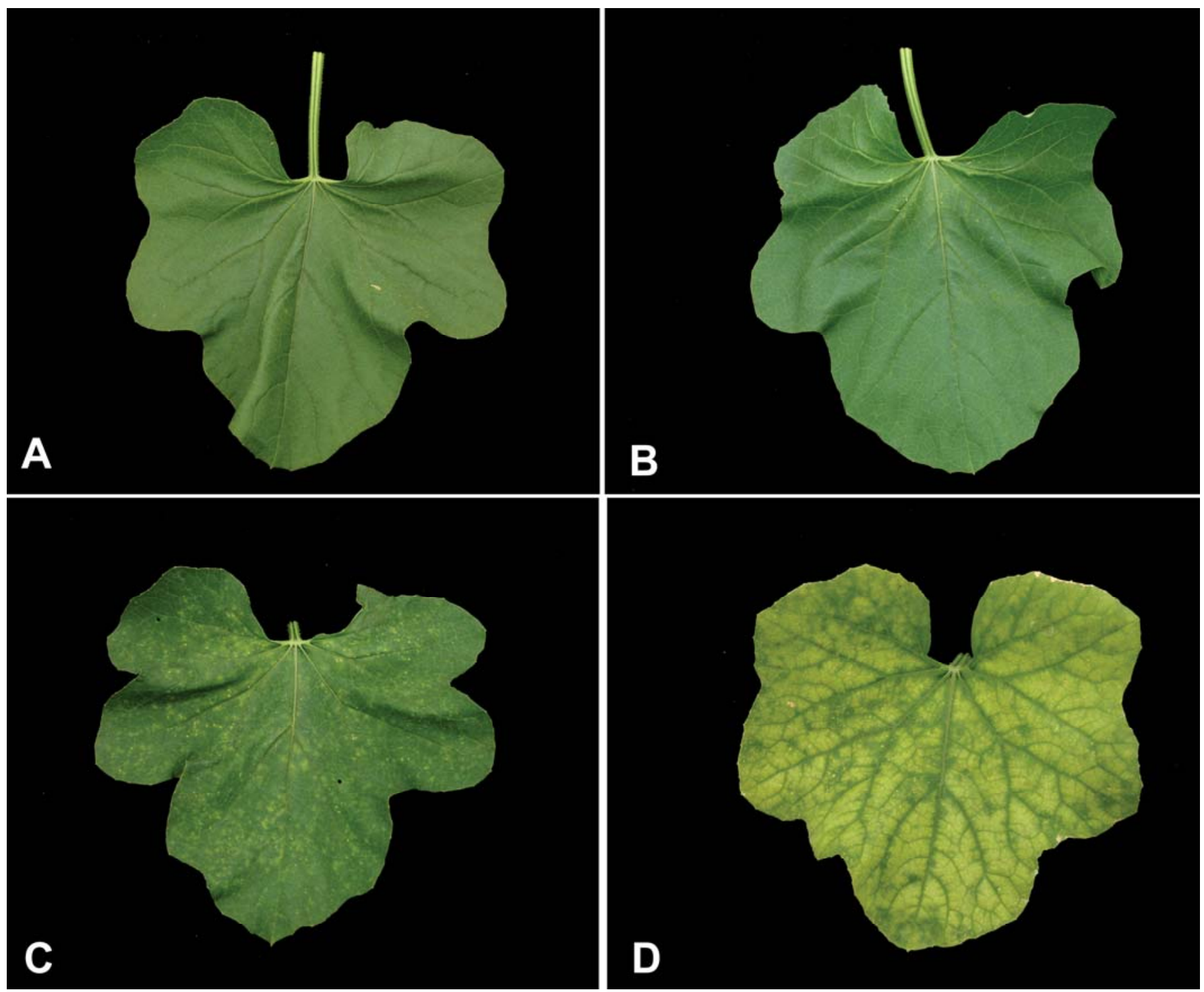

Fig. 1. Disease symptoms following inoculation of melon plants with Squash leaf curl virus (SLCV) and Watermelon chlorotic stunt virus (WmCSV). Melon plants were inoculated with A, whiteflies only; B, SLCV; C, WmCSV; and D, both SLCV and WmCSV. Pictures were taken 40 days after inoculation. 
tributed in the nethouse. Imidacloprid was applied through the drip-irrigation system at 4 and 8 weeks after transplanting. Following the appearance of female flowers, the walls of the nethouse were opened to allow entrance of honeybees to pollinate the flowers. Fruit were harvested three times: in the first and second harvests, only mature, orange fruit were collected; in the third harvest, all mature, orange, and immature green fruit were collected.

Viral DNA detection and quantification. Viral DNA accumulation levels in the apical leaves of infected plants in the nethouse trials were determined by dot-blot hybridization as described previously (17). A tissue sample $(0.1 \mathrm{~g})$ taken from the second completely unfolded leaf from the apex was collected and total plant DNA was extracted according to Dellaporta et al. (10). The extracted DNA was suspended in $50 \mu \mathrm{l}$ of ultrapure water, and 5 - $\mu$ l samples were dotted on a nylon membrane, which was than washed with $0.4 \mathrm{M} \mathrm{NaOH}$ to remove excess plant RNA. As an internal control, each sample was dotted twice on the membrane. For background determination, samples were taken from healthy control, noninoculated plants.

Two specific probes were used. A 1,158-nucleotide-length SLCV DNA-A fragment (corresponding to nucleotides 1987 to 496) and a 398-nucleotide-length WmCSV DNA-A fragment (corresponding to nucleotides 76 to 472) were cloned into the plasmid pGEM-T Easy (Promega Corp., Madison, WI). The cloned viral fragments served as a template for the production of an in vitro synthesized ${ }^{32} \mathrm{P}$-labeled viral riboprobe. Both probes were tested with DNA samples containing both viruses and were found to be virus specific; that is, the SLCV probe hybridized to SLCV samples but not to WmCSV samples, and the WmCSV probe hybridized to WmCSV samples but not to SLCV samples.

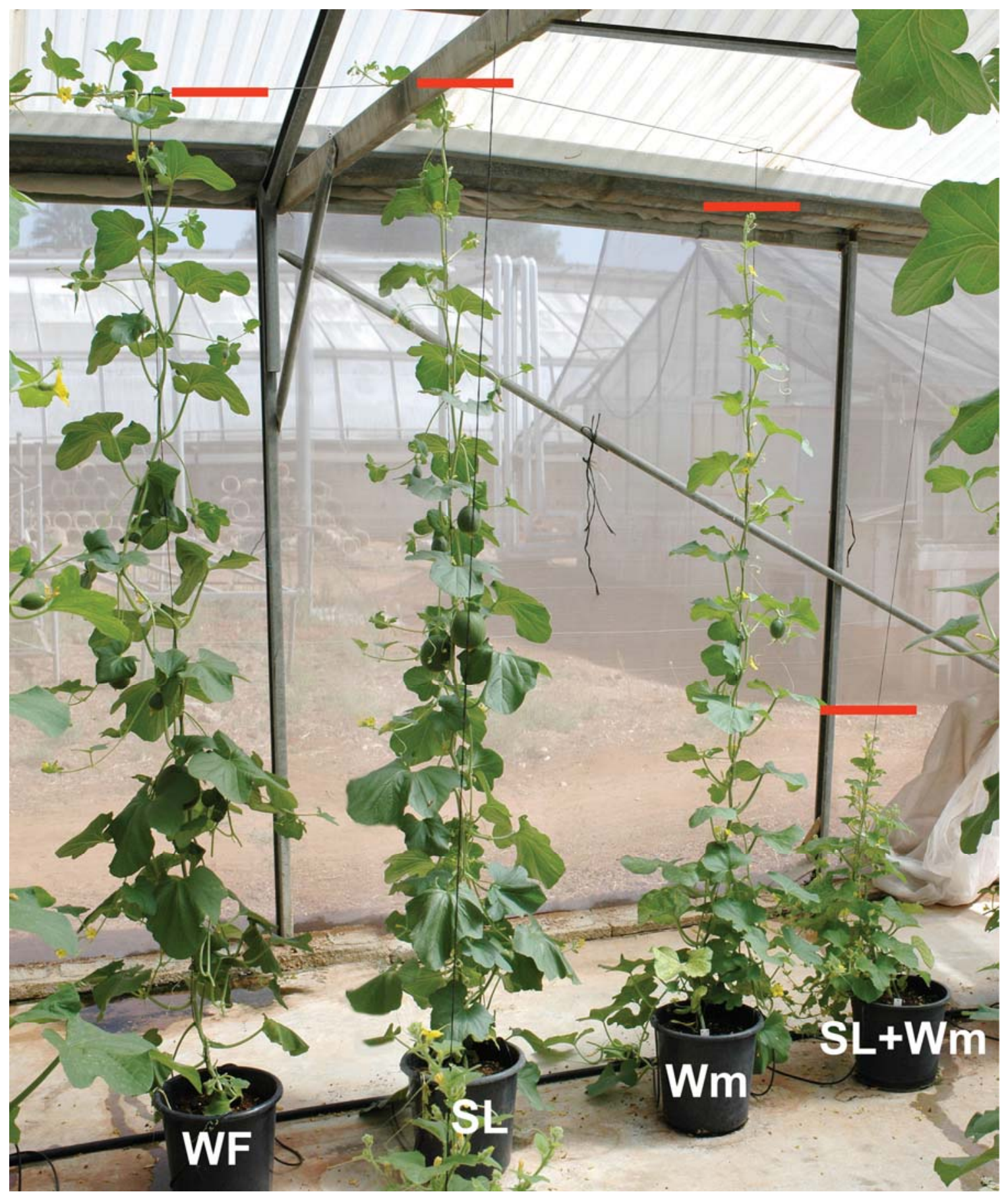

Fig. 2. Plant height following inoculation of melon plants with Squash leaf curl virus (SLCV) and Watermelon chlorotic stunt virus (WmCSV). Melon plants were inoculated with WF, whiteflies only; SL, SLCV; Wm, WmCSV; and SL+Wm, both SLCV and WmCSV. Pictures were taken 25 days after inoculation. 
The membrane was incubated overnight with the labeled viral riboprobe, rinsed under high stringency conditions, and exposed to a phosphorimager screen (Bio-imaging analyzer, FLA 5000; Fujifilm, Japan). The amount of viral DNA in each spot was quantitated and the background level was subtracted from each measurement. The amount of viral DNA in each sample was calculated according to a standard curve of viral DNA (1 to $50 \mathrm{ng}$ of either SLCV or WmCSV cloned viral DNA), which was dotted on a nylon membrane and reacted with the labeled viral riboprobe.

Statistical analysis was performed by means of a one-way analysis of variance test (SAS Institute, Cary, NC).

\section{RESULTS}

Effect of double inoculation on symptom development. Disease symptoms started to appear on the melon plants 7 to 10 days after inoculation. SLCV-infected plants initially showed symptoms of mild leaf curling and some chlorotic lesions. However, within 2 to 3 weeks of the first appearance of symptoms, the plants recovered and the symptoms completely disappeared (Fig. 1). WmCSV-infected plants usually developed symptoms by 10 days after inoculation. The symptoms initially appeared as yellow pinpoints that turned into large chlorotic lesions with time. Plants infected with both viruses expressed disease symptoms first, usually within 7 days after inoculation. The symptoms started as yellow pinpoints that grew rapidly and quickly turned the entire leaf yellow (Fig. 1).

Another pronounced visual impact of the dual infection was on plant height (Fig. 2; Table 1). Plants that were treated with both viruses were obviously stunted. WmCSV alone also adversely affected plant height to a lesser extent, and inoculation with SLCV alone had little or no effect on plant height (Table 1).

Effect of double inoculation on yield and fruit quality. The whitefly-only treated and SLCV-infected plants had yields that were similar to those of the untreated plants (Table 2). Inoculation with WmCSV tended to reduce yield but only in one summer experiment was this reduction statistically significant. However, inoculation with both viruses induced a yield reduction in all the experiments of 10 to $33 \%$ in the spring experiments and 30 to $87 \%$ in the summer experiments, when compared with the control

TABLE 1. Effect of double inoculation with Watermelon chlorotic stunt virus (WmCSV) and Squash leaf curl virus (SLCV) on melon plant height ${ }^{\mathrm{z}}$

\begin{tabular}{lcccrc}
\hline & \multicolumn{3}{c}{ Average plant height $(\mathrm{cm} \pm$ SEM $)$} \\
\cline { 2 - 3 } \cline { 5 - 6 } Treatment & \multicolumn{2}{c}{ Spring experiments } & & \multicolumn{1}{c}{ Summer experiments } \\
\cline { 2 - 3 } \cline { 5 - 6 } Control & 16 DAI & 22 DAI & & 16 DAI & 22 DAI \\
Whiteflies & $150 \pm 3.2$ & $200 \pm 3.3$ & & $110 \pm 3.8$ & $179 \pm 4.7$ \\
SLCV & $146 \pm 3.4$ & $204 \pm 3.3$ & & $91 \pm 2.5$ & $160 \pm 3.4$ \\
WmCSV & $129 \pm 4.7$ & $173 \pm 4.6$ & & $100 \pm 3.2$ & $173 \pm 6.1$ \\
SLCV+WmCSV & $108 \pm 4.9$ & $150 \pm 8.0$ & & $79 \pm 3.1$ & $142 \pm 6.2$ \\
\hline
\end{tabular}

${ }^{\mathrm{z}} \mathrm{SEM}=$ standard error of mean and DAI $=$ days after inoculation. untreated plants. The differences in fruit size among the treatments were not as marked (Table 2).

Fruit of the control, whitefly-treated, or SLCV-infected plants all went through the normal process of fruit maturation for muskmelon. As the fruit approached maturity, they developed a "netting" typical of muskmelon and changed from green to orange. Treating the plants with nonviruliferous whiteflies or inoculation with SLCV did not effect these changes in appearance. Inoculation with $\mathrm{WmCSV}$ resulted in some of the fruit not producing a complete netting (Fig. 3C), while others did not finish the color transition from green to orange (Fig. 3D). However, the fruit that were most affected were from plants inoculated with both WmCSV and SLCV. None produced netting and a large number of these fruit had shape deformations, too (Fig. $3 \mathrm{E}$ and $\mathrm{F})$.

Accumulation of viral DNA. Except for one point in time, SLCV DNA accumulated to higher levels in the dual-infected plants than in single-infected plants (Figs. 4 and 5). Only at 6 days after inoculation (DAI) in the spring experiment did SLCV DNA accumulate to the same level in the dual- or single-infected plants. At the other time points in the spring experiment, accumulation levels in the dual-infected plants were two to three times higher than in the single-infected (Fig. 4). In the singleinfected plants, SLCV DNA reached the highest level at 6 DAI and declined with time until 24 DAI, with a small increase at 18 DAI. The same pattern occurred in the dual infection but, in the dual infection, the highest accumulation level was at 18 rather than 6 DAI, and the decrease in viral DNA level from 6 to 24 DAI was attenuated (Fig. 4).

The same phenomenon was observed in the summer experiment but to a greater extent (Fig. 5). Although SLCV DNA accumulated to very low levels in the single-infected plants at all time points, its level in the dual-infected plants was 20 - to 60 -fold higher (Fig. 5).

Looking at accumulation of WmCSV DNA, the situation was different; specifically, except for one point in time, viral DNA levels were the same in the single- and dual-infected plants (Figs. 5 and 6). In the spring experiment, only at 12 DAI was WmCSV DNA level higher in the dual-infected plants than in the singleinfected plants. At the rest of the time points, viral DNA accumulated to the same level in both single- and dual-infected plants (Fig. 6). The same was true for the summer experiment. WmCSV DNA accumulated to the same level in both single- and dualinfected plants (Fig. 5). Interestingly, in the summer, WmCSV DNA accumulated to a higher level than did SLCV DNA whereas, in the spring, both viruses reached similar DNA accumulation levels (Figs. 4 to 6).

\section{DISCUSSION}

The results presented here demonstrate that the disease symptoms induced by the dual infection of WmCSV and SLCV are more severe than the symptoms induced by each virus alone. Four disease parameters were measured: symptom severity, plant height, fruit yield, and fruit appearance. SLCV by itself induced

TABLE 2. Effect of double inoculation with Watermelon chlorotic stunt virus (WmCSV) and Squash leaf curl virus (SLCV) on melon plant yield and fruit size ${ }^{\mathrm{Z}}$

\begin{tabular}{|c|c|c|c|c|c|c|c|c|}
\hline \multirow[b]{3}{*}{ Treatment } & \multicolumn{4}{|c|}{ Average total yield per plant $(\mathrm{kg} \pm \mathrm{SEM})$} & \multicolumn{4}{|c|}{ Average fruit weight $(\mathrm{kg} \pm \mathrm{SEM})$} \\
\hline & \multicolumn{2}{|c|}{ Spring } & \multicolumn{2}{|c|}{ Summer } & \multicolumn{2}{|c|}{ Spring } & \multicolumn{2}{|c|}{ Summer } \\
\hline & Exp. I & Exp. II & Exp. I & Exp. II & Exp. I & Exp. II & Exp. I & Exp. II \\
\hline Control & $3.7 \pm 0.3$ & $3.4 \pm 0.2$ & $3.0 \pm 0.2$ & $3.0 \pm 0.2$ & $1.4 \pm 0.1$ & $1.9 \pm 0.1$ & $1.2 \pm 0.06 \mathrm{a}$ & $1.2 \pm 0.1$ \\
\hline Whiteflies & $3.5 \pm 0.4$ & $3.7 \pm 0.3$ & $\ldots$ & $2.5 \pm 0.1$ & $1.4 \pm 0.1$ & $1.8 \pm 0.2$ & $\ldots$ & $1.1 \pm 0.1$ \\
\hline SLCV & $3.7 \pm 0.5$ & $2.7 \pm 0.4$ & $3.2 \pm 0.1$ & $3.1 \pm 0.2$ & $1.5 \pm 0.1$ & $1.2 \pm 0.2$ & $1.1 \pm 0.05 \mathrm{a}$ & $1.3 \pm 0.1$ \\
\hline WmCSV & $3.0 \pm 0.5$ & $3.1 \pm 0.3$ & $2.1 \pm 0.1$ & $2.6 \pm 0.1$ & $1.3 \pm 0.2$ & $1.5 \pm 0.3$ & $0.8 \pm 0.07 \mathrm{~b}$ & $1.2 \pm 0.1$ \\
\hline $\mathrm{SLCV}+\mathrm{WmCSV}$ & $3.3 \pm 0.5$ & $2.3 \pm 0.2$ & $0.4 \pm 0.1$ & $2.1 \pm 0.2$ & $1.3 \pm 0.1$ & $1.5 \pm 0.1$ & $0.3 \pm 0.07 \mathrm{c}$ & $1.0 \pm 0.1$ \\
\hline
\end{tabular}

${ }^{\mathrm{z}} \mathrm{SEM}=$ standard error of mean and Exp. = experiment. 
mild symptoms in melon plants, with the plants initially showing symptoms but then seeming to recover fully, and the virus had no effect on plant height, yield, and fruit quality. WmCSV induced more marked disease symptoms as well as a $13 \%$ height reduction in the spring whereas, in the summer, there was no height reduction. Significant yield reduction occurred in one of the summer experiments and some of the fruit did not fully develop netting. Following dual infection, however, the disease symptoms were severe and the plants were reduced in height by 20 to $25 \%$. Yield was reduced, on average, by $40 \%$, none of the fruit developed netting, and many were deformed.

In a synergistic interaction between two viruses, as opposed to additive effects, the presence of one virus causes an elevation in titer of the other. This indeed occurred in the dual infection of WmCSV and SLCV in melon: the presence of WmCSV promoted an increase in the SLCV DNA level (Figs. 4 and 5). In the spring experiment, SLCV DNA level was two to three times higher in dual-infected plants compared with SLCV-infected plants where- as, in the summer experiment, SLCV DNA level in the dualinfected plants was 10- to 50-fold higher than in single-infected plants. However, the DNA level of WmCSV stayed the same regardless of presence or absence of SLCV.

Such an increase in the level of SLCV DNA can be achieved by either an increase of SLCV replication in the infected cell or by an increase in the number of SLCV-infected cells. Although our results do not reveal the mechanism of the synergistic interaction, it is tempting to speculate that the increase in SLCV accumulation is due to WmCSV suppression of posttranscriptional gene silencing (PTGS). Support for this hypothesis comes from the observation that melon plants recover from SLCV infection (Table 1 and 2; Figs. 1 and 2). Following inoculation with SLCV, melon plants initially showed mild disease symptoms that disappeared with time, SLCV DNA level decreased with time, and SLCV had no affect on yield. Recovery is usually associated with PTGS and with the production of virus-derived small-interfering RNA (siRNA) molecules $(5,32)$. Although recovery is an unusual

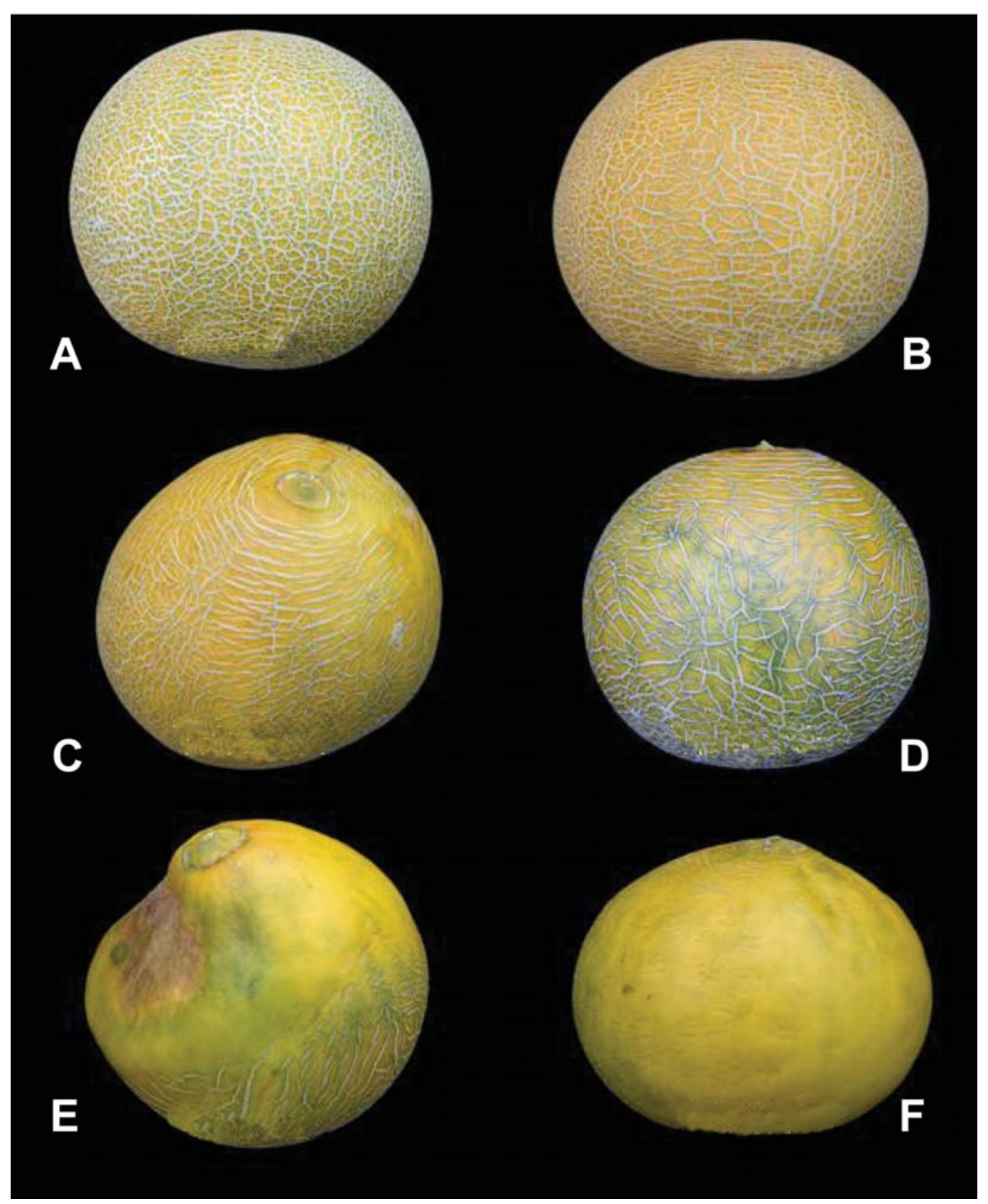

Fig. 3. Fruit quality following inoculation of melon plants with Squash leaf curl virus (SLCV) and Watermelon chlorotic stunt virus (WmCSV). Melon plants were inoculated with A, whiteflies only; B, SLCV; $\mathbf{C}$ and D, WmCSV; and $\mathbf{E}$ and F, both SLCV and WmCSV. Picture was taken 60 days after inoculation. 
phenomenon for begomoviruses (32), it has been demonstrated before for African cassava mosaic virus and Nicotiana benthamiana (9). It was shown that, although disease symptoms and viral DNA accumulation decreased, accumulation of virus-specific siRNA increased. Chellappan et al. (9) postulated that, in the recovering plants, the increase in virus-specific siRNA downregulated viral mRNAs and, as a consequence, reduced viral replication. Recently, recovery was demonstrated with two more begomoviruses. Hagen et al. (12) demonstrated recovery of cantaloupe and watermelon plants following inoculation with Cucurbit leaf crumple virus. However, in this case, virus-specific siRNA levels were positively correlated with viral DNA and recovered tissue had lower levels of both viral DNA and virus-specific siRNA. It was also shown that viral DNA was highly methylated in recovered tissue, and the decrease in viral replication was attributed to the high methylation level (12). The same results were observed in the recovery of pepper plants following infection with Pepper golden mosaic virus; that is, reduction of disease symptoms and level of viral DNA was accompanied with a decrease in virus-specific siRNA and with a high level of viral DNA methylation $(8,28)$.
Most plants do not recover following begomovirus infection, probably because begomoviruses are able to suppress the host antiviral silencing response (5). Hence, one can postulate that WmCSV suppresses the melon plant-silencing defense and, as a result, SLCV can replicate. As a result of being infected by both viruses, the plant is afflicted with severe disease symptoms.

There appears to have been a seasonal influence on the severity of dual infection, with greater severity in the summer experiment (Table 2). The main difference between the seasons was the temperature during vegetative plant development prior to fruiting. Specifically, temperatures were higher during this growth phase in the summer experiment, especially at night (Table 3). In May, which is the first month of the spring experiments, the temperature ranged from $16^{\circ} \mathrm{C}$ at night to $28.5^{\circ} \mathrm{C}$ during the day whereas, in August, the first month of the summer experiments, the temperature ranged from $23^{\circ} \mathrm{C}$ at night to $32^{\circ} \mathrm{C}$ during the day. For most viruses, including begomoviruses $(8,20)$, the younger the infected host is at the time of inoculation the more severe is the viral disease that develops. Apparently, because the young plants are more sensitive to viruses, climatic conditions can have a stronger influence on symptom development than when inocu-
6 DAI

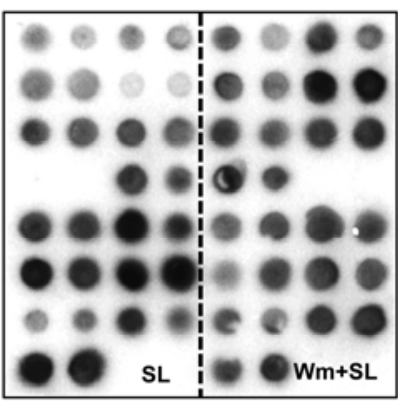

12 DAI

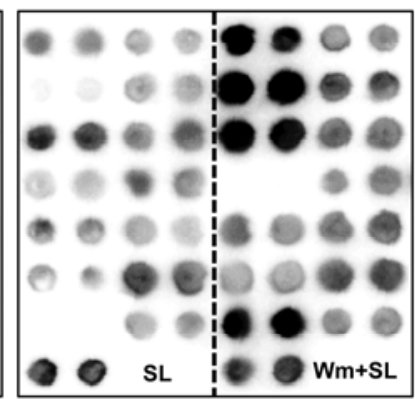

18 DAl

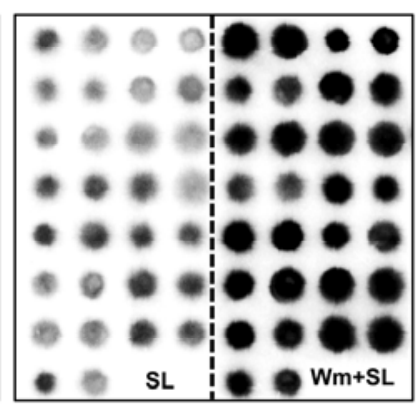

24 DAl

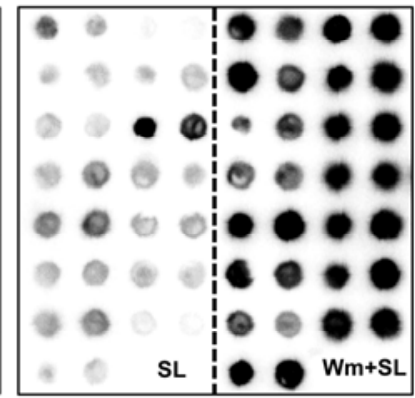

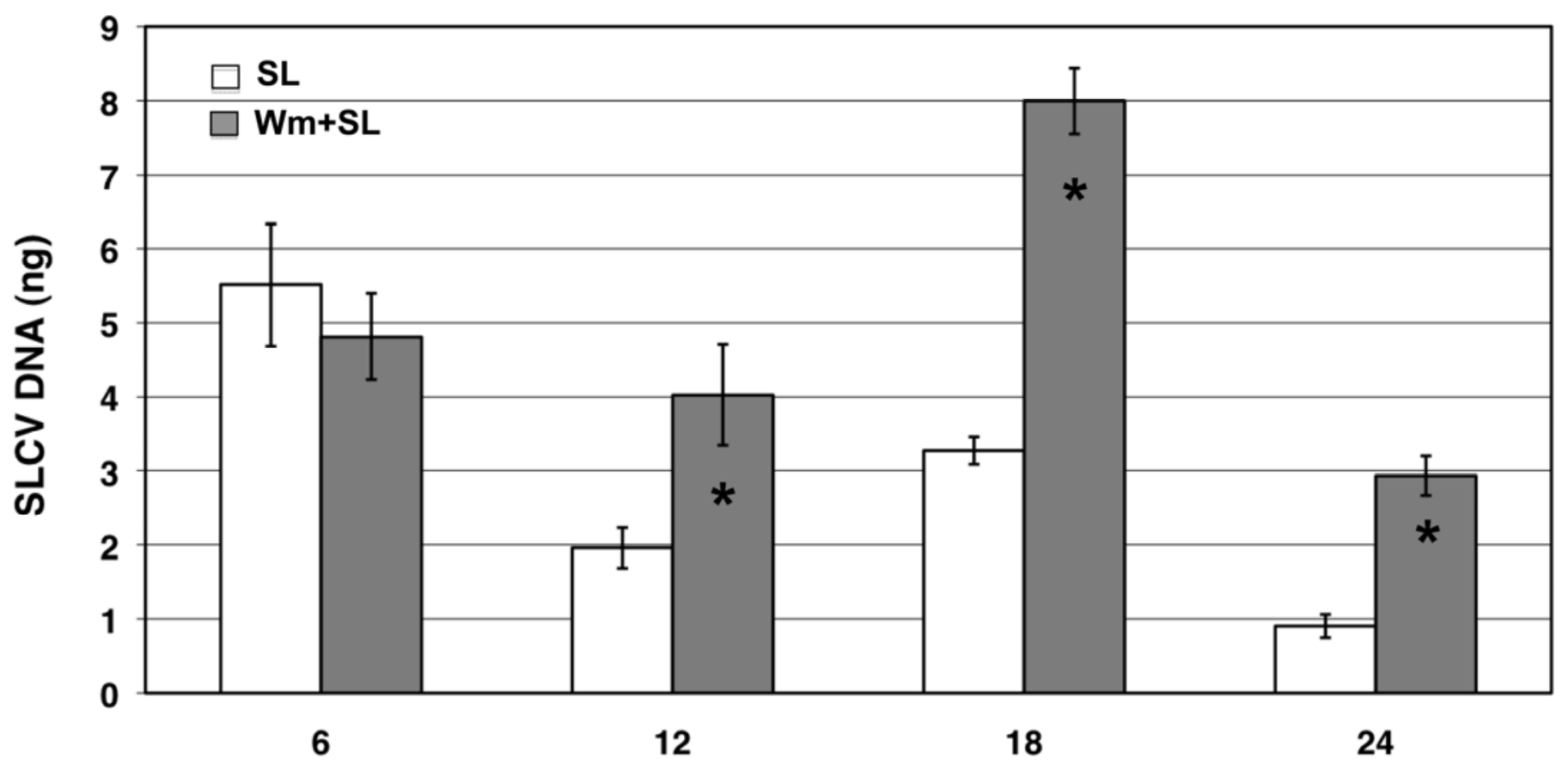

\section{Days after inoculation}

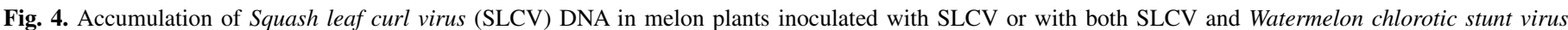

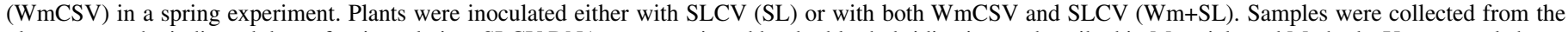

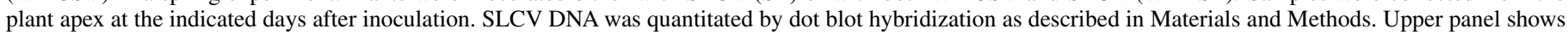

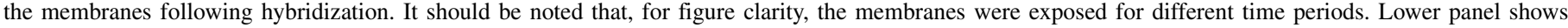

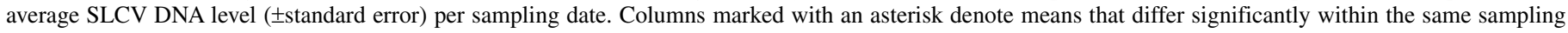
date $(P<0.05)$. 
lated plants reach the reproductive phase. Begomoviruses are found mostly in tropical and subtropical climates and are more destructive at higher temperatures. Likewise, populations of their vector, Bemisia species, are favored by high temperatures (23). Disease severity of Tomato yellow leaf curl virus (TYLCV), another begomovirus, is strongly favored by high temperatures $(15,18)$. TYLCV-induced yield reduction was double when plants were evaluated in the field during a hot season than when evaluated in a greenhouse during a cooler season.

Both SLCV and WmCSV are vectored by a number of Bemisia species, which are attracted to cucurbit plants in general and especially to melon plants. This makes mixed infection of cucurbits with these two viruses a likely event in our region. On top of the harsh results due to a synergistic interaction between these two viruses, mixed infection also poses a serious risk that these two viruses might recombine and produce a more destructive virus. In order for a recombination event to occur, mixed infection of the same cell is a prerequisite. Indeed, Morilla et al. (24) demonstrated that mixed infection of TYLCV and Tomato yellow leaf curl Sardinia virus occur in at least $20 \%$ of infected nuclei of tomato plants. Studies in the last decade on different hosts and in different geographical regions, such as cassava mosaic disease in Africa, cotton leaf curl disease in Pakistan, and tomato leaf curl disease in the Mediterranean, provided ample evidence for the ability of begomoviruses to recombine as a result of mixed infection $(6,25,26)$.

It is also safe to assume that, like TYLCV, given time, both viruses will eventually spread throughout the countries bordering the Mediterranean Sea. Cucurbit crops typically are grown in the open field and trying to protect them will become a considerably greater challenge. The synergistic interaction characterized here could potentially pose a serious threat to melon production.
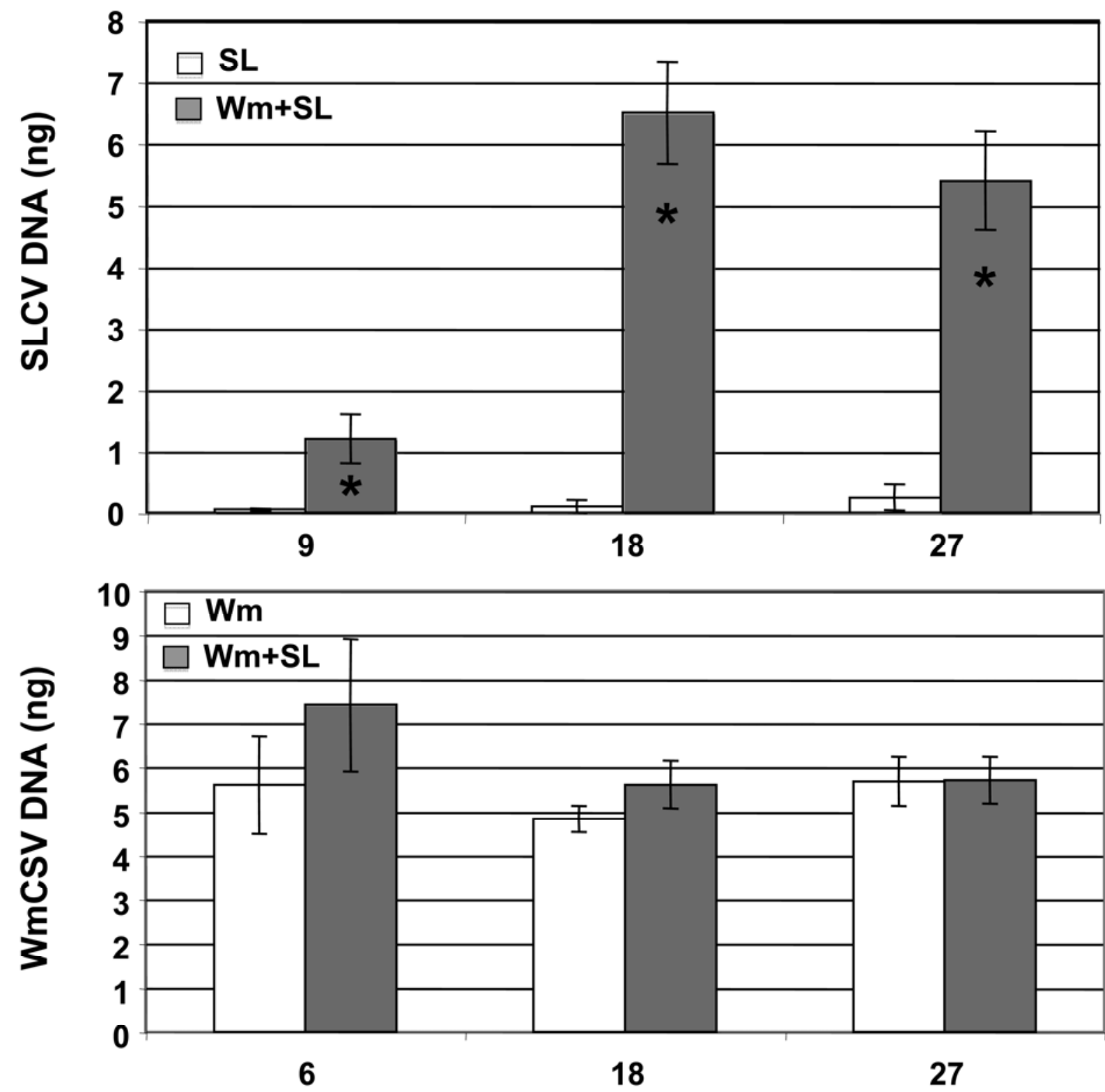

Days after inoculation

Fig. 5. Accumulation of Squash leaf curl virus (SLCV) and Watermelon chlorotic stunt virus (WmCSV) DNA in melon plants inoculated with either SLCV (SL), WmCSV (Wm), or with both WmCSV and SLCV (Wm+SL) in a summer experiment. Samples were collected from the plant apex at the indicated days after inoculation. SLCV DNA (upper panel) or WmCSV DNA (lower panel) was quantitated by dot blot hybridization as described in Materials and Methods. Columns marked with an asterisk denote means that differ significantly within the same sampling date $(P<0.05)$. 


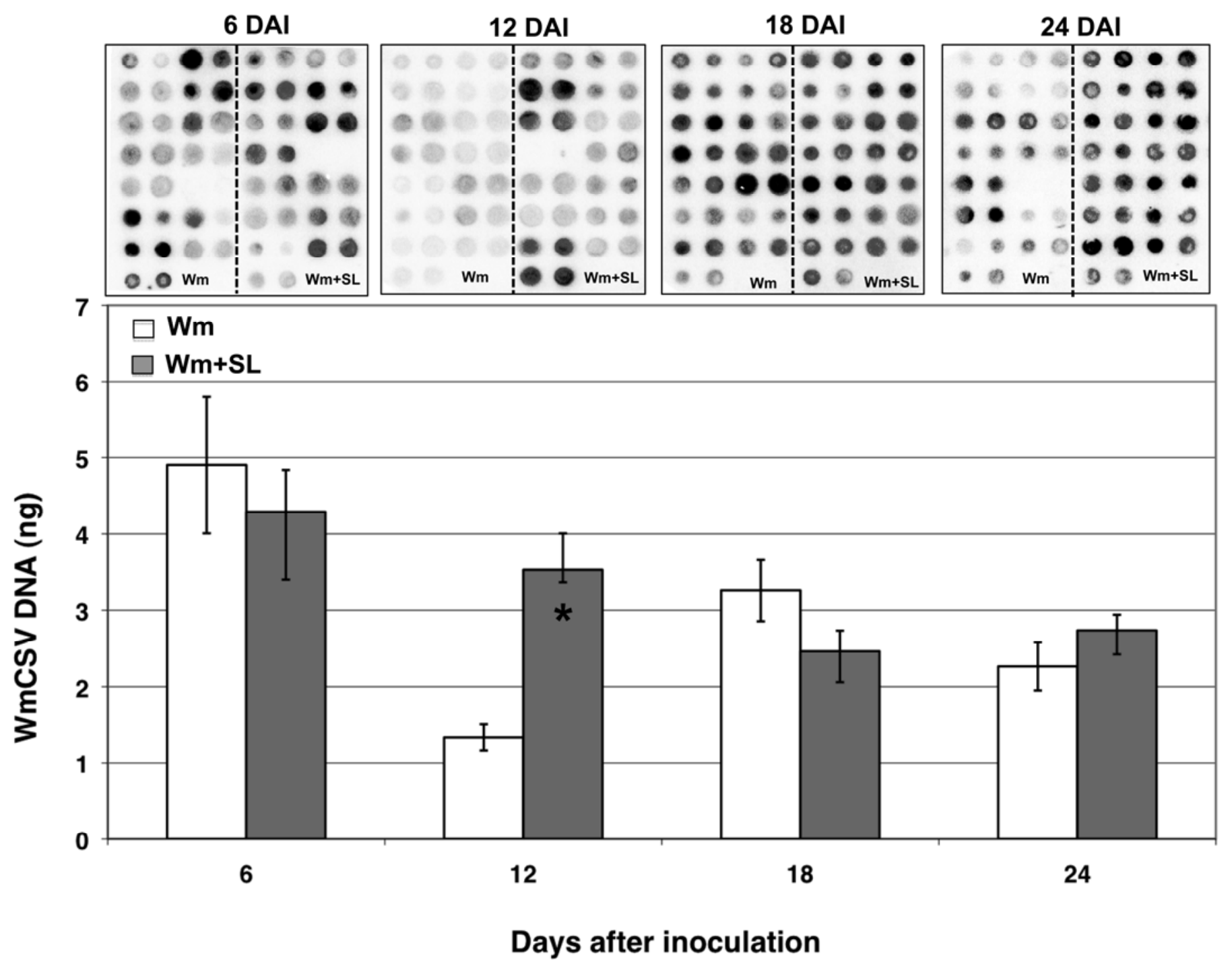

Fig. 6. Accumulation of Watermelon chlorotic stunt virus (WmCSV) DNA in melon plants inoculated with Squash leaf curl virus (SLCV) or with both SLCV and WmCSV in a spring experiment. Plants were inoculated either with WmCSV (Wm) or with both WmCSV and SLCV (Wm+SL). Samples were collected from the plant apex at the indicated days after inoculation. WmCSV DNA was quantitated by dot blot hybridization as described in Materials and Methods. Upper panel shows the membranes following hybridization. It should be noted that, for figure clarity, the membranes were exposed for different time periods. Lower panel shows average WmCSV DNA level per sampling date. Columns marked with an asterisk denote means that differ significantly within the same sampling date $(P<0.05)$.

TABLE 3. Average temperature at the experimental site, Bet Dagan, Israel

\begin{tabular}{llcc}
\hline & \multicolumn{2}{c}{ Mean temperature $\left({ }^{\circ} \mathrm{C} \pm \mathrm{SEM}\right)^{\mathrm{y}}$} & \\
\cline { 2 - 3 } Experiment, month & Minimum & Maximum & Days $>30^{\circ} \mathrm{C}^{\mathrm{z}}$ \\
\hline Summer 2005 & & & \\
$\quad$ August & $23.0 \pm 0.2$ & $31.6 \pm 0.1$ & 30 \\
September & $21.1 \pm 0.3$ & $31.0 \pm 0.3$ & 16 \\
October & $16.9 \pm 0.6$ & $27.8 \pm 0.5$ & 3 \\
Summer 2006 & & & \\
$\quad$ August & $22.6 \pm 0.3$ & $31.8 \pm 0.2$ & 29 \\
September & $21.1 \pm 0.3$ & $31.3 \pm 0.4$ & 22 \\
October & $17.9 \pm 0.3$ & $28.3 \pm 0.5$ & 0 \\
Spring 2006 & & & \\
May & $16.1 \pm 0.4$ & $26.0 \pm 0.4$ & 1 \\
June & $19.7 \pm 0.3$ & $27.7 \pm 1.2$ & 9 \\
July & $22.4 \pm 0.2$ & $30.8 \pm 0.1$ & 19 \\
Spring 2007 & & & \\
May & $17.9 \pm 0.5$ & $28.5 \pm 0.7$ & 8 \\
June & $20.2 \pm 0.3$ & $29.8 \pm 0.6$ & 10 \\
July & $22.5 \pm 0.3$ & $31.7 \pm 0.2$ & 23 \\
\hline
\end{tabular}

${ }^{y} \mathrm{SEM}=$ standard error of mean.

${ }^{\mathrm{z}}$ Number of days with maximum temperature $>30^{\circ} \mathrm{C}$.

\section{ACKNOWLEDGMENTS}

We thank H. Paris (Newe Ya'ar Research Center, ARO) for critically reviewing this manuscript. This work was supported in part by USAIDMERC grant no. M26-063 to M. Lapidot. Contribution number 118/2010 from the Agricultural Research Organization, Volcani Center, Bet Dagan, Israel.

\section{LITERATURE CITED}

1. Abudy, A., Sufrin-Ringwald, T., Dayan-Glick, C., Guenoune-Gelbart, D., Livneh, O., Zaccai, M., and Lapidot, M. 2010. Watermelon chlorotic stunt and Squash leaf curl begomoviruses-new threats to cucurbit crops in the Middle East. Israel J. Plant Sci. 58:33-42.

2. Al-Musa, A., Anfoka, G., Misbeh, S., Abhary, M., and Ahmad, F. H. 2008. Detection and molecular characterization of Squash leaf curl virus (SLCV) in Jordan. J. Phytopathol. 156:311-316.

3. Antignus, Y., Lachman, O., Pearlsman, M., Omar, S., Yunis, H., Messika, Y., Uko, O., and Koren, A. 2003. Squash leaf curl virus-a new illegal immigrant from the Western Hemisphere and a threat to cucurbit crops in Israel. Phytoparasitica 31:415.

4. Bananej, K., Ahoonmanesh, A., and Kheyr-Pour, A. 2002. Host range of an Iranian isolate of Watermelon chlorotic stunt virus as determined by whitefly-mediated inoculation and agroinfection, and its geographical 
distribution. J. Phytopathol. 150:423-430.

5. Bisaro, D. M. 2006. Silencing suppression by geminivirus proteins. Virology 344:158-168.

6. Briddon, R. W. 2003. Cotton leaf curl disease, a multicomponent begomovirus complex. Mol. Plant Pathol. 4:427-434.

7. Brown, J. K., Idris, A. M., Alteri, C., and Stenger, D. C. 2002. Emergence of a new cucurbit-infecting begomovirus species capable of forming viable reassortments with related viruses in the Squash leaf curl virus cluster. Phytopathology 92:734-742.

8. Carrillo-Tripp, J., Lozoya-Gloria, E., and Rivera-Bustamante, R. F. 2007. Symptom remission and specific resistance of pepper plants after infection by Pepper golden mosaic virus. Phytopathology 97:51-59.

9. Chellappan, P., Vanitharani, R., and Fauquet, C. M. 2004. Short interfering RNA accumulation correlates with host recovery in DNA virus-infected hosts, and gene silencing targets specific viral sequences. J. Virol. 78:7465-7477.

10. Dellaporta, S. L., Wood, J., and Hicks, J. B. 1983. Maize DNA miniprep. Plant Mol. Biol. Rep. 1:19-21.

11. Fauquet, C. M., Briddon, R. W., Brown, J. K., Moriones, E., Stanley, J., Zerbini, M., and Zhou, X., 2008. Geminivirus strain demarcation and nomenclature. Arch. Virol. 153:783-821.

12. Hagen, C., Rojas, M. R., Kon, T., and Gilbertson, R. L. 2008. Recovery from Cucurbit leaf crumple virus (family Geminiviridae. Genus Begomovirus) infection is an adaptive antiviral response associated with changes in viral small RNAs. Phytopathology 98:1029-1073.

13. Idris, A. M., Abdel-Salam, A., and Brown, J. K. 2006. Introduction of the new world Squash leaf curl virus to squash (Cucurbita pepo) in Egypt: A potential threat to important food crops. Plant Dis. 90:1262.

14. Jones, D. R. 2003. Plant viruses transmitted by whiteflies. Eur. J. Plant Pathol. 109:195-219.

15. Lapidot, M., Ben Joseph, R., Cohen, L., Machbash, Z., and Levy, D. 2006. Development of a scale for evaluation of Tomato yellow leaf curl virus-resistance level in tomato plants. Phytopathology 96:1404-1408.

16. Lapidot, M., and Friedmann, M. 2002. Breeding for resistance to whitefly-transmitted geminiviruses. Ann. Appl. Biol. 140:109-127.

17. Lapidot, M., Friedmann, M., Lachman, O., Yehezkel, A., Nahon, S., Cohen, S., and Pilowsky, M. 1997. Comparison of resistance level to tomato yellow leaf curl virus among commercial cultivars and breeding lines. Plant Dis. 81:1425-1428.

18. Lapidot, M., Goldray, O., Ben Joseph, R, Cohen, S., Friedmann, M., Shlomo, A., Nahon, S., Chen, L., and Pilowsky, M. 2000. Breeding tomatoes for resistance to tomato yellow leaf curl begomovirus. EPPO Bull. 30:317-321.

19. Latham, J. R., and Wildon, A. K. 2008. Transcomplementation and synergism in plants: implications for viral transgenes? Mol. Plant Pathol. 9:85-103.

20. Levy, D., and Lapidot, M. 2008. Effect of plant age at inoculation on expression of genetic resistance to tomato yellow leaf curl virus. Arch. Virol. 153:171-179.

21. Mansoor, S., Briddon, R. W., Zafar, Y., and Stanley, J. 2003. Geminivirus disease complexes: an emerging threat. Trends Plant Sci. 8:128-134.

22. Mendez-Lozano, J., Torres-Pacheco, I., Fauquet, C. M., and RiveraBustamante, R. F. 2003. Interactions between geminiviruses in a naturally occurring mixture: Pepper huasteco virus and Pepper golden mosaic virus. Phytopathology 92:270-277.

23. Morales, F. J., and Jones, P. G. 2004. The ecology and epidemiology of whitefly-transmitted viruses in Latin America. Virus Res. 100:57-65.

24. Morilla, G., Krenz, B., Jeske, H., Bejarano, E. R., and Wege, C. 2004. Tete-a-tete of Tomato yellow leaf curl virus and Tomato yellow leaf curl Sardinia virus in single nuclei. J. Virol. 78:10715-10723.

25. Morionese, E., Garcia-Andres, S., and Navas-Castilo, J. 2007. Recombination in the TYLCV complex: A mechanism to increase genetic diversity. Implications for plant resistance development. Pages 119-140 in: Tomato Yellow Leaf Curl Virus Disease. H. Czosnek, ed. Springer, The Netherlands.

26. Pita, J. S., Fondong, V. N., Sangare, A., Otim-Nape, G. W., Ogwal, S., and Fauquet, C. M. 2001. Recombination, pseudorecombination and synergism of geminiviruses are determinant keys to the epidemics of severe cassava mosaic disease in Uganda. J. Gen. Virol. 82:655-665.

27. Prus, G., Ge, X., Shi, X. M., Carrington, J. C., and Vance, V. B. 1997. Plant viral synergism: the potyviral genome encodes a broad-range pathogenicity enhancer that transactivates replication of heterologous viruses. Plant Cell 9:859-868.

28. Rodriguez-Negrete, E., Carrillo-Tripp, J., and Rivera-Bustamante, R. F 2009. RNA silencing against geminiviruses: Complementary action of posttranscriptional gene silencing and transcriptional gene silencing in host recovery. J. Virol. 83:1332-1340.

29. Rojas, M. R., Hagen, C., Lucas, W. J., and Gilbertson, R. G. 2005. Exploiting chinks in the plant's armor: Evolution and emergence of geminiviruses. Annu. Rev. Phytopathol. 43:361-394.

30. Roossinck, M. J. 2005. Symbiosis versus competition in plant virus evolution. Nat. Rev. Microbiol. 3:917-924.

31. Seal, S. E., van den Bosch, F., and Jeger, M. J. 2006. Factors influencing begomovirus evolution and their increasing global significance: Implications for sustainable control. Crit. Rev. Plant Sci. 25:23-46.

32. Vanitharani, R., Chellappan, P., and Fauquet, C. M. 2005. Geminiviruses and RNA silencing. Trends Plant Sci.10:144-151.

33. Varma, A., and Malathi, V. G. 2003. Emerging geminivirus problems: A serious threat to crop production. Ann. Appl. Biol. 142:145-164. 